\title{
THE
}

2016

\section{Bivariate Autoregressive State-Space Modeling of Psychophysiological Time Series Data}

\author{
Daniel M. Smith \\ University of Rhode Island \\ Mohammadreza Abtahi \\ University of Rhode Island \\ Amir Mohammad Amiri \\ University of Rhode Island \\ Kunal Mankodiya

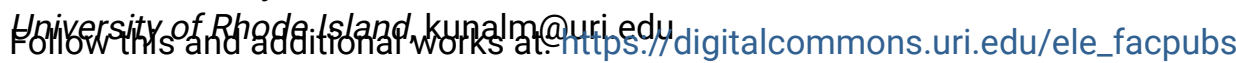

The University of Rhode Island Faculty have made this article openly available.

Please let us know how Open Access to this research benefits you.

This is a pre-publication author manuscript of the final, published article.

Terms of Use

This article is made available under the terms and conditions applicable towards Open Access

Policy Articles, as set forth in our Terms of Use.

\section{Citation/Publisher Attribution}

Smith, D. M., Abtahi, M., Amiri, A. M., \& Mankodiya, K. (2016, August 16-20). Bivariate Autoregressive State-Space Modeling of Psychophysiological Time Series Data. 2016 38th Annual International Conference of the IEEE Engineering in Medicine and Biology Society (EMBC). Orlando, FL, USA. doi: 10.1109/EMBC.2016.7591932

Available at: http://dx.doi.org/10.1109/EMBC.2016.7591932

This Conference Proceeding is brought to you for free and open access by the Department of Electrical, Computer, and Biomedical Engineering at DigitalCommons@URI. It has been accepted for inclusion in Department of Electrical, Computer, and Biomedical Engineering Faculty Publications by an authorized administrator of DigitalCommons@URI.For more information, please contact digitalcommons-group@uri.edu. 


\title{
Bivariate Autoregressive State-Space Modeling of Psychophysiological Time Series Data
}

\author{
Daniel M. Smith ${ }^{1,3}$, Mohammadreza Abtahi ${ }^{2}$, Amir Mohammad Amiri ${ }^{2}$, and Kunal Mankodiya ${ }^{2,3}$
}

\begin{abstract}
Heart rate (HR) and electrodermal activity (EDA) are often used as physiological measures of psychological arousal in various neuropsychology experiments. In this study, we analyze HR and EDA data collected from four participants during a cognitive task known as the Paced Auditory Serial Addition Test (PASAT). Using a state space modeling approach to time series analysis, we evaluate the effect of an exogenous input, i.e., the stimulus presentation rate which was increased systematically during the experimental task. Participants differed in several parameters characterizing the way psychological arousal was experienced during the task. Increasing the stimulus presentation rate was associated with an increase in EDA in participants 2 and 4 . The effect on HR was positive for participant 2 and negative for participants 3 and 4.
\end{abstract}

\section{INTRODUCTION}

Psychological arousal, behavior, and emotion are related to responses in the sympathetic autonomic nervous system. Specific effects of sympathetic activity include increased heart rate and sweating, dilation of lungs, blood vessels, and pupils, decreases in digestion and salivation, and adrenaline release. Of particular relevance here is the relationship between arousal, heart rate (HR), and electrodermal activity (EDA). Perhaps due to the heart's salience to many body functions, studies investigating $\mathrm{HR}$ and arousal have been mixed. Some have reported an increase in HR, while others have observed the opposite [1]. EDA, which reflects the activity of sweat glands in the skin, is a physiological indicator of sympathetic arousal. Many studies have found an increase in EDA associated with the presentation of arousing stimuli [2]ï [4]. Some investigators have found EDA to be more closely linked to arousal than HR [5]ї [6], and among studies aiming to classify emotions EDA is one of the most common physiological signals used [7]. Also important to the current study, which includes the analysis of EDA data from persons with suicidal tendencies, is a review by Thorell [8], which demonstrated the potential for electrodermal hyporeactivity to be a useful instrument for identifying suicide risk in depressed patients.

\section{METHODS}

\section{A. Participants and Data Collection}

Four participants gave informed consent to the protocol approved by the Butler Hospital Institutional Review Board. Physiological data including pulse oximetry, EDA, and respiration rate were collected from participants experiencing suicidal tendencies as they performed a cognitive task known

${ }^{1}$ Department of Psychology, ${ }^{2}$ Department of Electrical, Computer, and Biomedical Engineering, and ${ }^{3}$ Center for Health Monitoring and Intervention, The University of Rhode Island, Chafee Hall Third Floor, 142 Flagg Rd., Kingston, RI 02881 (e-mail: dansmith@uri.edu) as the Paced Auditory Serial Addition Test (PASAT). The PASAT is a neuropsychological test used to assess capacity and speed of information processing, including in investigations like the current study that use psychophysiological assessment. The PASAT requires participants to add numbers within a set time period. As the task progresses, participants are required to answer simple one-digit addition math problems as digits (stimuli) appeared on a screen over a 250-second period (see Fig. 1). The frequency of stimulus presentation was increased as follows. One stimulus was presented every 3.0 seconds for the first 150 seconds, every 1.5 seconds for the next 75 seconds, and every 1.0 second for the remaining 25 seconds. Alternatively, these presentation rates can be expressed as $0.33,0.67$, and 1.00 stimuli per second. Each stimulus appeared on the screen for 500 milliseconds regardless of presentation frequency. $\mathrm{HR}$ and EDA were sampled at rate of $1 \mathrm{kHz}$. These data were decimated to $1 \mathrm{~Hz}$ for analysis.

\section{B. Modeling Technique}

The aim of the study is to assess whether there are patterned responses that characterize the way each individual experiences psychological arousal during the cognitive task. To that end, the analytical objectives of the study are (1) to examine the dynamics of HR and EDA using state space time series analysis and (2) to investigate whether increasing the stimulus presentation rate is associated with increases in HR and EDA.

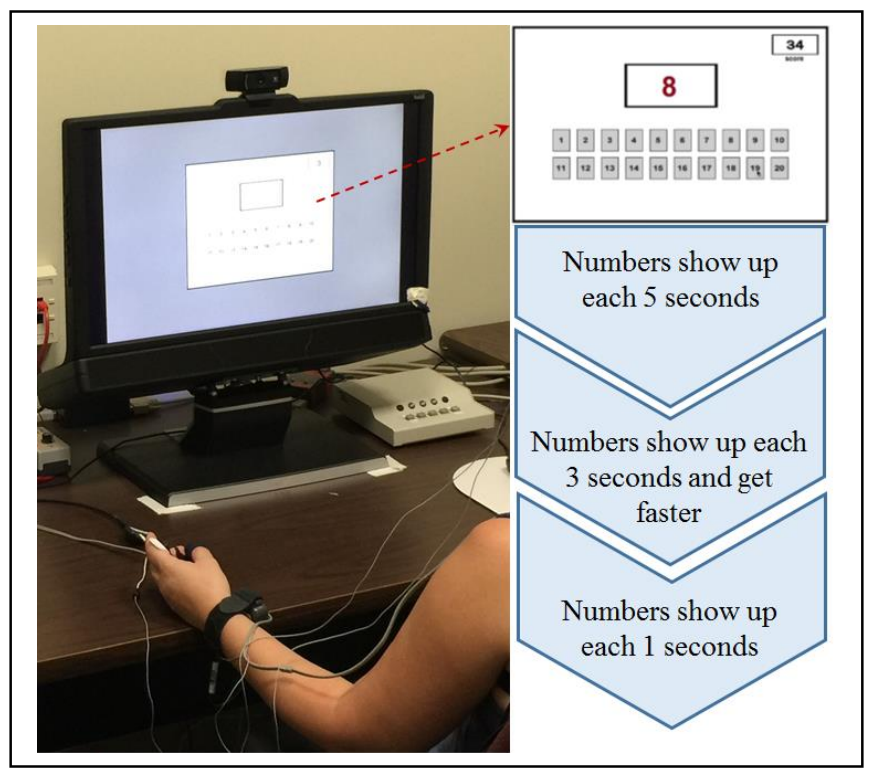

Figure 1. PASAT experimental setup. 
Bivariate time series of HR and EDA (see Fig. 2 and 3) were analyzed for each participant using a first-order autoregressive model with the stimulus presentation rate included as an exogenous input. The state and observation sub-models are represented by equations 1 and 2 , respectively.

$$
\begin{gathered}
X_{t}=A X_{t-1}+B u_{t}+\varepsilon_{t} ; \varepsilon_{t} \sim N(0, Q) \\
y_{t}=C X_{t}+\mu+\omega_{t} ; \omega_{t} \sim N(0, R)
\end{gathered}
$$

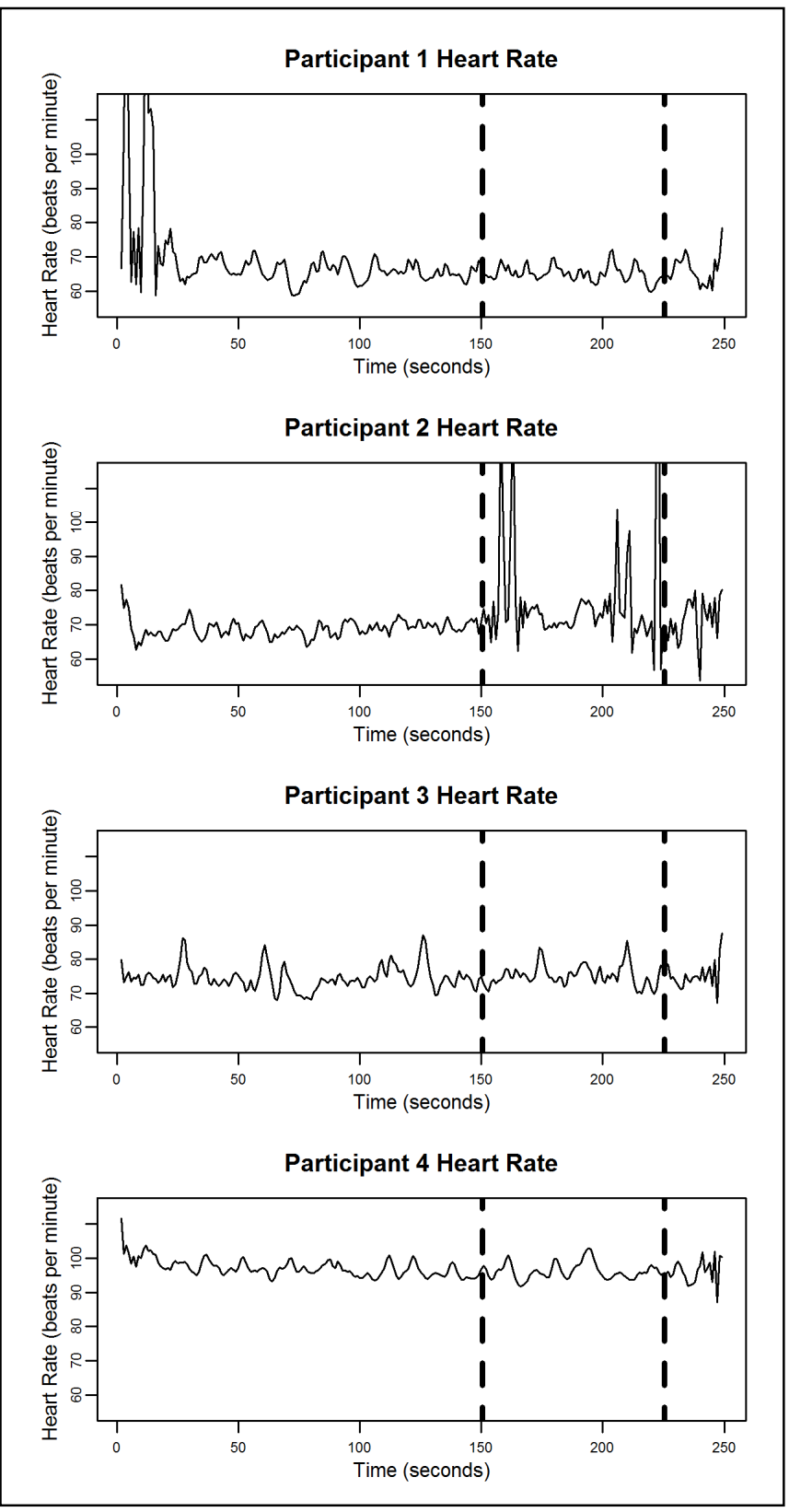

Figure 2. HR time series data for all participants. Vertical dashed lines show the time points at which the stimulus presentation rate increased.
- $\quad X_{t}$ and $X_{t-1}$ are $2 \times 1$ vectors of state variables for HR and EDA at times $t$ and $t-1$

- $A$ is a $2 \times 2$ transition matrix reflecting the autodependence of the state variables

- $u_{t}$ is a single exogenous input, the stimulus presentation rate at time $t$

- $\quad B$ is a $2 \times 1$ vector of regression coefficients relating the input $u_{t}$ to the state vector $X_{t}$

- $Q$ is a $2 \times 2$ covariance matrix of the dynamic errors, $\mathcal{E}_{t}$

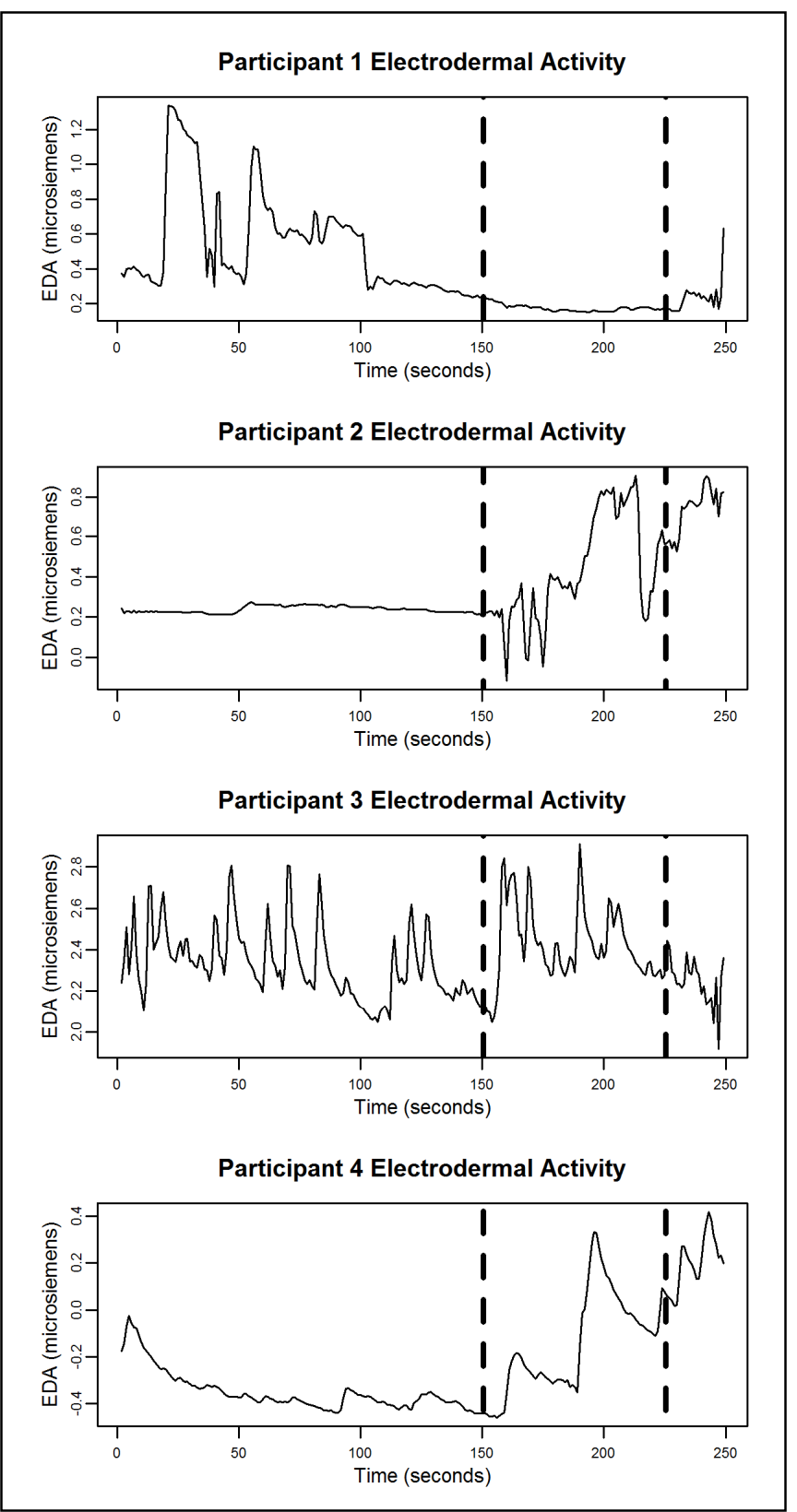

Figure 3. EDA time series data for all participants. Vertical dashed lines show the time points at which the stimulus presentation rate increased. 
- $y_{t}$ is a $2 \times 1$ vector of HR and EDA observations at time $t$

- $C$ is a $2 \times 2$ identity matrix relating the state variables, $X_{t}$, to the observed variables, $y_{t}$

- $\mu$ is a $2 \times 1$ vector reflecting the level (analogous to linear intercept) of HR and EDA

- $R$ is a $2 \times 2$ covariance matrix of the measurement errors, $\omega_{t}$

The software used in this analysis was the ñMARSSò (multivariate autoregressive state space) package in $\mathrm{R}$. MARSS uses the Kalman [9] filter and smoother to generate state variable estimates, which are outputted to a maximum likelihood algorithm for computation of parameter estimates and their standard errors. The optimization algorithm used in these analyses was the quasi-Newton Broydenï Fletcherï Goldfarbï Shanno (BFGS) method.

\section{RESUlts}

Parameter estimates and 95\% confidence intervals are shown in Table I. Parameters whose confidence interval does not span zero are statistically significant at a type I error rate of 0.05 . The A parameters reflect each variableôs first-order autoregressive process. All but one of these is positive and some of these reflect very strong autoregression (i.e., close to 1 , such as $A_{E D A}$ for participant 4). The $B$ parameters reflect substantively interesting relationships, i.e., the change in HR and EDA per unit increase in the stimulus presentation rate. Fig. 4 illustrates the changes in HR and EDA predicted by the $B$ estimates that were statistically significant. These parameters were not significant for participant 1, suggesting that her/his HR and EDA were unchanged across the increasing demands of the cognitive task. By contrast, both B parameters were positive and significant for participant 2, which indicates that this personô $\mathrm{HR}$ and EDA increased as

TABLE I. PARAMETER ESTIMATES AND CONFIDENCE INTERVALS

\begin{tabular}{|c|c|c|c|c|}
\hline \multirow{2}{*}{$\begin{array}{l}\text { Para- } \\
\text { meter }\end{array}$} & \multicolumn{4}{|c|}{ Participant } \\
\hline & 1 & 2 & 3 & 4 \\
\hline $\mathrm{A}_{\mathrm{HR}}$ & $\begin{array}{l}\mathbf{0 . 5 7 ^ { \mathrm { a } }} \\
(0.47,0.67)^{\mathrm{b}}\end{array}$ & $\begin{array}{l}\mathbf{0 . 2 6} \\
(0.13,0.38)\end{array}$ & $\begin{array}{l}\mathbf{0 . 2 4} \\
(0.11,0.38)\end{array}$ & $\begin{array}{l}\mathbf{- 0 . 2 2} \\
(-0.4,-0.04)\end{array}$ \\
\hline$A_{\text {EDA }}$ & $\begin{array}{l}\mathbf{0 . 9 4} \\
(0.90,0.97)\end{array}$ & $\begin{array}{l}\mathbf{0 . 9 0} \\
(0.85,0.94)\end{array}$ & $\begin{array}{l}\mathbf{0 . 6 5} \\
(0.60,0.69)\end{array}$ & $\begin{array}{l}\mathbf{0 . 9 6} \\
(0.94,0.98)\end{array}$ \\
\hline $\mathrm{B}_{\mathrm{HR}}$ & $\begin{array}{l}-4.56 \\
(-9.76,0.64)\end{array}$ & $\begin{array}{l}\mathbf{5 . 6 3} \\
(0.28,11.0)\end{array}$ & $\begin{array}{l}-\mathbf{- 0 . 7 5} \\
(-0.9,-0.6)\end{array}$ & $\begin{array}{l}\mathbf{- 5 . 4 2} \\
(-8.6,-2.2)\end{array}$ \\
\hline $\mathrm{B}_{\mathrm{EDA}}$ & $\begin{array}{l}-0.04 \\
(-0.09,0.02)\end{array}$ & $\begin{array}{l}\mathbf{0 . 0 6} \\
(0.01,0.11)\end{array}$ & $\begin{array}{l}-0.06 \\
(-0.15,0.02)\end{array}$ & $\begin{array}{l}\mathbf{0 . 0 4} \\
(0.02,0.06)\end{array}$ \\
\hline$\varepsilon_{\mathrm{HR}}$ & $\begin{array}{l}72.9 \\
(66.4,79.5)\end{array}$ & $\begin{array}{l}\mathbf{6 7 . 5} \\
(63.7,71.3)\end{array}$ & $\begin{array}{l}\mathbf{7 5 . 2} \\
(74.5,76.0)\end{array}$ & $\begin{array}{l}\mathbf{9 8 . 7} \\
(97.3,100)\end{array}$ \\
\hline$\varepsilon_{\mathrm{EDA}}$ & $\begin{array}{l}\mathbf{0 . 7 0} \\
(0.29,1.12)\end{array}$ & $\begin{array}{l}0.05 \\
(-0.16,0.26)\end{array}$ & $\begin{array}{l}\mathbf{2 . 4 3} \\
(2.30,2.57)\end{array}$ & $\begin{array}{l}\mathbf{- 0 . 7 3} \\
(-1.0,-0.5)\end{array}$ \\
\hline \multicolumn{5}{|c|}{ Error Variances } \\
\hline Ů & $\begin{array}{l}\mathbf{8 6 . 6} \\
(72.0,102)\end{array}$ & $\begin{array}{l}\mathbf{8 7 . 4} \\
(72.7,103)\end{array}$ & $\begin{array}{l}\mathbf{1 8 . 5} \\
(15.4,21.9)\end{array}$ & $\begin{array}{l}0 \\
(\mathrm{NA}, \mathrm{NA})\end{array}$ \\
\hline 巳̈DA & $\begin{array}{l}\mathbf{0 . 0 0 7} \\
(6 e-3,8 e-3)\end{array}$ & $\begin{array}{l}\mathbf{0 . 0 0 4 8} \\
(4 e-3,5 e-3)\end{array}$ & $\begin{array}{l}\mathbf{0 . 0 2 5} \\
(2 \mathrm{e}-2,3 \mathrm{e}-2)\end{array}$ & $\begin{array}{l}\mathbf{0 . 0 0 1} \\
(1 \mathrm{e}-3,1 \mathrm{e}-3)\end{array}$ \\
\hline$\gamma_{\mathrm{HR}}$ & $\begin{array}{l}0 \\
(\mathrm{NA}, \mathrm{NA})\end{array}$ & $\begin{array}{l}0 \\
(\mathrm{NA}, \mathrm{NA})\end{array}$ & $\begin{array}{l}0 \\
(\mathrm{NA}, \mathrm{NA})\end{array}$ & $\begin{array}{l}\mathbf{2 1 . 4} \\
(17.8,25.3)\end{array}$ \\
\hline$\gamma_{\mathrm{EDA}}$ & $\begin{array}{l}0 \\
(\mathrm{NA}, \mathrm{NA})\end{array}$ & $\begin{array}{l}0 \\
(\mathrm{NA}, \mathrm{NA})\end{array}$ & $\begin{array}{l}0 \\
(\mathrm{NA}, \mathrm{NA})\end{array}$ & $\begin{array}{l}0 \\
(\mathrm{NA}, \mathrm{NA})\end{array}$ \\
\hline
\end{tabular}

a. Estimates in bold are statistically significant at the 0.05 Type I error rate. b. Values shown in parentheses are $95 \%$ confidence limits.

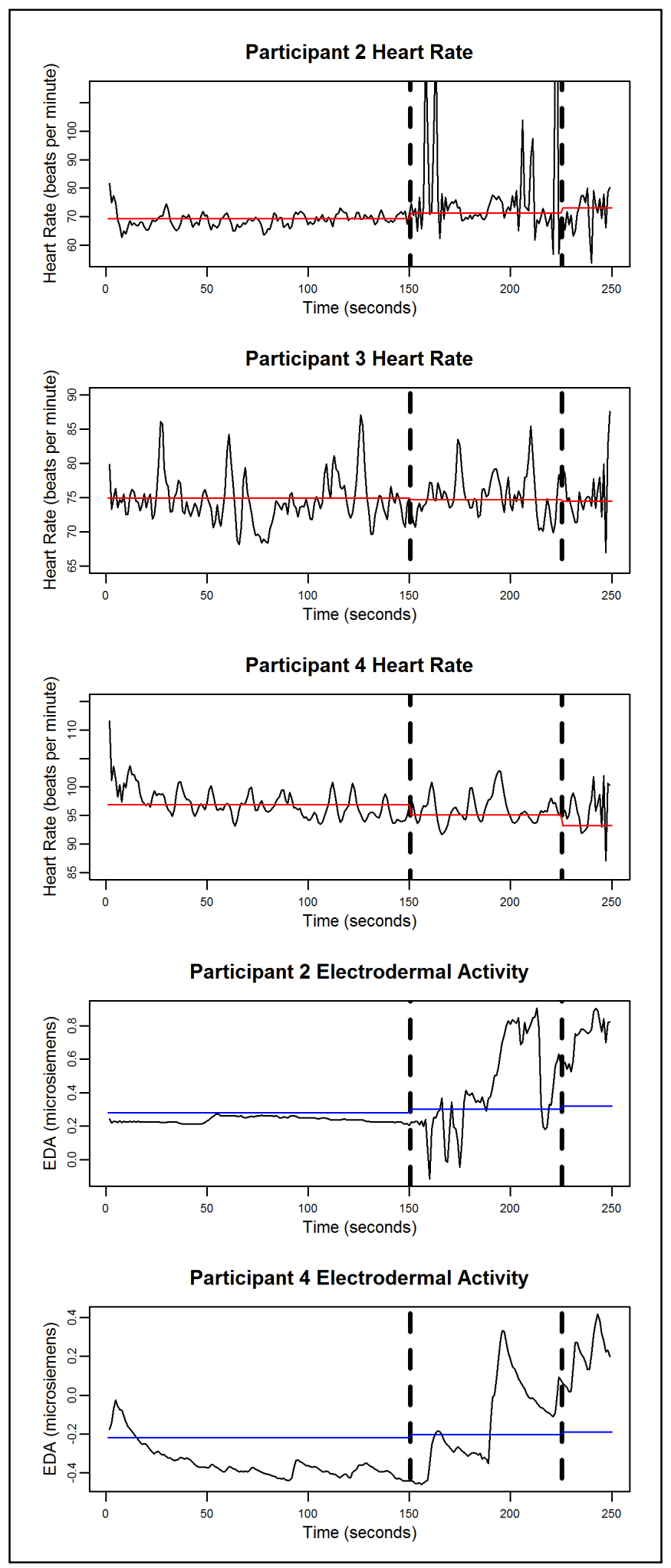

Figure 4. Changes in HR or EDA predicted by the models that had significant B parameters. Vertical dashed lines show the time points at which the stimulus presentation rate increased. 
the stimulus presentation rate increased. The same can be said of EDA for participant 4. Unexpectedly, $B_{H R}$ was negative and significant for participants 3 and 4, from which it can be concluded that HR decreased for these participants as stimulus presentation rate increased. The $\varepsilon$ parameters are not intended to have substantive value, but they are reflective of individual differences in participantsômean HR and EDA. For example, from these we can see that the mean HR is higher for participant 4 than the others. The error variances also differed greatly between the four participants. In most cases, the measurement error variance was very close to 0 .

\section{Discussion AND CONCLUSION}

In this study, we used a state-space modeling framework to execute autoregressive time series analysis on bivariate time series of HR and EDA. Performing four separate analyses enabled the estimation of participant-specific parameter estimates that reflected each personôs unique patterns of change in HR and EDA across the 250-second cognitive task. Assessing the significance and direction of the B parameters, it is apparent that each participant experienced the cognitive task differently in terms of physiological response. While the task was anticipated to induce psychological arousal manifested in increases in HR and EDA, there was a significant, positive effect in only three cases out of eight (i.e., participant 2 HR and EDA and participant 4 EDA). Similar to others who have reported mixed results with arousal and HR [1], in our study there were two cases of negative effects on HR, in participants 3 and 4. In sum, the state space modeling framework is a convenient and advantageous approach for handling many aspects of psychophysiological data analysis, including autodependence, exogenous inputs, multiple sources of error, and multiple observed variables.

\section{ACKNOWLEDGMENT}

We would like to convey our thanks to Dr. Michael Armey and his research group for helping us collect the data.

\section{REFERENCES}

[1] A.-M. Brouwer et al., ñPerceiving blocks of emotional pictures and sounds: effects on physiological variables, ò Front Hum Neurosci, vol. 7, no. 295, pp. 1-10, June 2013.

[2] W. Boucsein, ñElectrodermal activity as an indicator of emotional processes, Ò Emot Sci, vol. 2, no. 1, pp. 1-25, 1999.

[3] S. Khalfa et al., ñEvent-related skin conductance responses to musical emotions in humans, òNeurosci Lett, vol. 328, no. 2, pp. 145-149, Aug. 2002.

[4] P. Tremayne and R. J. Barry, ñElite pistol shooters: physiological patterning of best vs. worst shots, ò Int J Psychophysiol, vol. 41, no. 1, pp. 19-29, May 2001.

[5] R. J. Croft et al., ñDifferential relations between heart rate and skin conductance, and public speaking anxiety,òJ Behav Ther Exp Psy, vol. 35, no. 3, pp. 259-271, Sept. 2004.

[6] B. L. Wilkes, C. J. Gonsalvez, and A. Blaszczynski, ñCapturing SCL and HR changes to win and loss events during gambling on electronic machines,òInt J Psychophysiol, vol. 78, no. 3, pp. 265-272, Dec. 2010.

[7] G. Chanel et al., ñShort-term emotion assessment in a recall paradigm,òInt J Hum-Comput St, vol. 67, no. 8, pp. 607-627, Aug. 2009.
[8] L. Thorell, ñValid electrodermal hyporeactivity for depressive suicidal propensity offers links to cognitive theory,ò Acta Psychiat Scand, vol. 119, no. 5, pp. 338-349, May 2009.

[9] R. E. Kalman, ñNew results in linear filtering and prediction theory,ò J Basic Eng, ser. D, vol. 83, pp. 95-108, Mar. 1961. 